VIII Congresso Brasileiro de Informática na Educação (CBIE 2019)

Anais do XXV Workshop de Informática na Escola (WIE 2019)

\title{
ENSINO DE ALGORITMOS E LÓGICA DE PROGRAMAÇÃO PARA MENINAS NO ENSINO BÁSICO
}

\author{
Maria L. Machado Silva ${ }^{1}$, Diego Teixeira Witt ${ }^{1}$, Andreia Marini ${ }^{2}$ \\ ${ }^{1}$ Departamento de Eng. de Computação - Instituto Federal Catarinense (IFC) \\ São Bento do Sul - SC- Brazil \\ ${ }^{2}$ Departamento de Sistemas de Informação - Instituto Federal do Paraná (IFPR) \\ Palmas - PR - Brazil \\ machadosilvam42@gmail.com,andreia.marini@ifpr.edu.br, \\ diego.witt@ifc.edu.br
}

Abstract. The paper focuses on basic education in order to provide elements for more girls students to access certain areas of knowledge and, consequently, to be interested in areas where they are minority. The methodology is based on conversation wheels, workshops and discussions with topics related to the introduction of algorithms and programming logic. The activity applied in the programming workshop proved to be a way to arouse the interest of students in a predominantly male area. The actions implemented aim to encourage and support girls from public schools in São Bento Sul-SC, awaken the interest to follow their studies in the fields of Science, Technology, Engineering and Mathematics.

Resumo. O artigo é voltado para a educação básica a fim de oferecer elementos para que mais estudantes meninas acessem determinadas áreas do conhecimento e, dessa maneira, possam interessar-se por áreas onde são minoria. A metodologia se baseia em rodas de conversa, oficinas $e$ discussões com temas relacionados à introdução de algoritmos e lógica de programação. A atividade aplicada na oficina de programação se mostrou como uma forma de despertar o interesse das estudantes em uma área predominantemente masculina. As ações executadas visam incentivar e apoiar meninas das escolas públicas de São Bento Sul - SC, assim despertando o interesse em seguirem seus estudos nas áreas das Ciências, Tecnologia, Engenharia e Matemática.

\section{Introdução}

O interesse no ensino de algoritmos e lógica de programação é uma preocupação de inúmeros pesquisadores, particularmente devido às várias dificuldades enfrentadas pelos alunos, independente de gênero, em seu primeiro contato com conceitos básicos de programação. 
As disciplinas introdutórias de algoritmos e lógica de programação apresentam altas taxa de reprovação e evasão, muitas vezes devido às dificuldades em aprender os conteúdos, ou a falta de motivação demonstrada por muitos estudantes [Souza, Batista e Barbosa 2016].

Este artigo apresenta uma abordagem de introdução do ensino de algoritmos e lógica de programação aplicada como parte de um projeto que visa aumentar a representação feminina em áreas científico-tecnológicas. Assim, o artigo está organizado da seguinte forma: a próxima seção apresenta os trabalhos correlatos. Na seção 3 descreve-se os detalhes da metodologia de ensino adotada. Uma discussão em relação aos resultados é apresentada na seção 4. Seguido, são descritas as conclusões e sugestões para trabalhos futuros.

\section{Trabalhos relacionados}

Entre as soluções pedagógicas sugeridas para superar algumas das dificuldades dos estudantes no processo de ensino-aprendizagem de algoritmos e lógica de programação encontra-se na literatura recomendações para o uso de jogos e softwares educacionais.

O trabalho de Oliveira, Ribeiro e Machado [2015] apresenta uma proposta de ensino de lógica de programação com auxílio de robôs. Os autores observam que a robótica pode ser um recurso importante para promover o interesse da criança, especialmente, quando aplicada por meio de jogos e na introdução do ensino de lógica de programação [Oliveira, Ribeiro e Machado 2015].

Silva e Cavalcanti [2018] buscam oferecer evidências estatísticas sobre a efetividade do uso do software educacional Robomind, com relação aos possíveis ganhos de aprendizado de programação e sua capacidade em diminuir a evasão. Os autores destacam que os ganhos de aprendizado não devem ser os únicos parâmetros utilizados para avaliar o uso de uma ferramenta educacional. Também podem ser considerados elementos como a motivação e o engajamento dos estudantes, os quais não foram considerados para esse trabalho [Silva e Cavalcanti 2018] .

De maneira geral, aprender programação é importante, pois estimula a criatividade, autonomia e desenvolve o raciocínio lógico dos estudantes, bem como a capacidade de resolução de problemas e promovendo o trabalho colaborativo [Mattos, Ferreira e Anacleto 2016].

\section{Metodologia}

O trabalho apresentado, ocorre dentro da execução do projeto: "Mulheres que mudarão o mundo". Este projeto envolve várias atividades nas escolas participantes: rodas de conversa, oficinas, confecção do mural, exposição fotográfica e encerramento que proporcionará novas ações para as comunidades envolvidas. Essas atividades foram previamente organizadas ocorrendo de março de 2019 a novembro de 2019.

O público inicial participante do projeto foram 22 estudantes de duas escolas públicas de Educação Básica do Ensino Médio que se encontram nas periferias de São 
VIII Congresso Brasileiro de Informática na Educação (CBIE 2019)

Anais do XXV Workshop de Informática na Escola (WIE 2019)

Bento do Sul. A escola de Educação Básica Prefeito Carlos Zipperer Sobrinho. localizada no Bairro Centenário, e a escola Educação Básica Celso Ramos Filho, localizada no bairro Oxford. As escolas escolhidas estão em regiões periféricas do município, recebendo estudantes de várias localidades e de condições distintas de renda, sendo a maior parte de famílias de classe média-baixa.

A oficina de programação foi dividida em duas etapas: a primeira com a implantação de sequência didática; a segunda com a execução de uma atividade em laboratório de informática, por meio de pseudo-linguagem de programação. Corresponde a dois encontros para cada escola, a primeira etapa em março e a segunda etapa em maio de 2019. No primeiro encontro, após uma sensibilização em relação a participação das mulheres em atividades predominantemente masculinas, foi perguntado às estudantes quantas mulheres programadoras de computadores elas conheciam e se elas gostariam de experimentar atividades desse tipo. A pergunta norteadora nessa fase foi: "como podemos dar ordens ao computador?"

As alunas foram convidadas a participar de um jogo colaborativo, por meio do qual puderam vivenciar e compreender a ideia de uma linguagem de programação. Com a utilização de fita crepe foi desenhada no chão uma malha, como um tabuleiro de 6 linhas e 6 colunas (ou dimensionada conforme o espaço disponível na sala). Foram indicados os locais de entrada (linha 1, coluna 1), local de saída (linha 6, coluna 6) e indicados pelas participantes, alguns obstáculos em linhas e colunas aleatórias.

Para iniciar o jogo, foram definidas duplas de programadora e robô, sendo que a primeira tem o papel de dar ordens ao robô, enquanto a segunda deverá apenas seguí-las. O objetivo da dupla é encontrar a melhor maneira de chegar até a saída da malha para obter a premiação deixada no local. Em seguida, as duplas são alternadas e os níveis de dificuldade são crescentes. A Figura 1 apresenta um exemplo da execução da primeira etapa da oficina de programação de computadores.

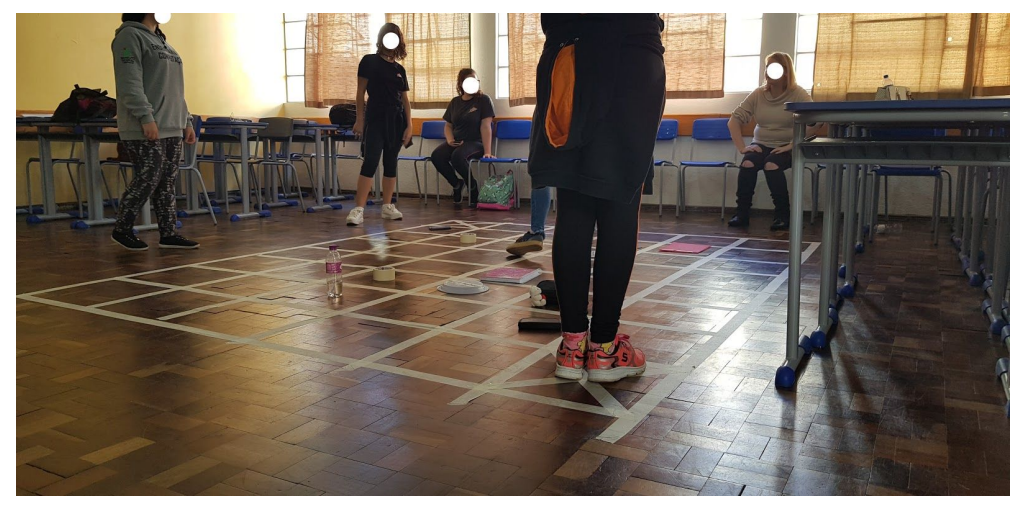

Figura 1. Malha para ensino de lógica de programação.

Ao final, foi promovida uma discussão geral, em relação a maneira como a linguagem de programação serve como método para que possamos estabelecer comunicação com o computador e dar ordens do que ele deve fazer. 
Para a segunda etapa da oficina de programação de computadores as alunas foram convidadas visitar os laboratórios de informática do Instituto Federal Catarinense - campus São Bento do Sul. Retomando assim a questão norteadora, em que introduziu-se os principais métodos de abordagem de algoritmos, em que explicou-se às suas principais características, semelhanças e diferenças.

Posteriormente, foi elaborado um algoritmo simples em conjunto com as meninas na forma de descrição narrativa. Após isso, foi dada uma folha para que as meninas organizassem o mesmo algoritmo em forma de fluxograma. Essa atividade foi promovida para estimular um novo tipo de estruturação de algoritmos, mais objetiva que a descrição narrativa e mais natural que o pseudocódigo. Por fim, buscou-se explanar dúvidas encontradas e abriu-se espaço para discussão sobre as dificuldades encontradas na escrita do código.

\section{Resultados e Discussões}

Um dos primeiros resultados vivenciados foi a evasão de participantes. Inicialmente o projeto iniciou com um total de 22 estudantes, somando as duas escolas em que o projeto foi aplicado, tendo uma baixa de $63,63 \%$ das estudantes. Esse fato ocorreu em decorrência de dois principais fatores. O primeiro deles é o estímulo oferecido pelas instituições onde foi aplicado, que não possuíam um profissional de referência, que incentiva-se a participação. O outro fator está relacionado principalmente com relação a temática de estudo, voltado às ciências exatas, área que tem pouca representatividade feminina para às estudantes. A motivação se mostra um item crucial, pois afeta às áreas de engenharias, matemática, física, assim tendem a apresentar mais opiniões negativas, não demonstrando interesse e classificando como sem sentido e desnecessárias, como a programação [Simon et al., 2009].

As oficinas de programação utilizaram como artifício, a representatividade de mulheres importante para a ciência da computação, uma das estudantes relata que a oficina, em suas palavras, “....apresentou uma área predominantemente masculina e me fez compreender que se eu quero chegar a determinado lugar, com força e paciência eu consigo"1. Outra estudante frisa que "todas as oficinas foi(sic) boas demais, porque você aprende que as mulheres também pode(sic) ser o que quiserem ser, e podem ter voz"'2. Esses relatos são estimulantes, pois mostram que o objetivo de buscar uma representatividade das mulheres na ciência é um caminho a ser construído e uma realidade que pode ser alcançada.

Ainda, a atividade promoveu que às meninas também aprendessem estratégias para a resolução de problemas, comunicar informações úteis, raciocínio lógico. Assim que as atividades e a articulação desenvolvidas possam fortalecer a imagem de que as áreas das Ciências, Tecnologia, Engenharia e Matemática devem também ser populadas pelas mulheres, possibilitando um novo olhar científico que promova o enriquecimento da produtividade.

\footnotetext{
${ }^{1}$ Transcrição na íntegra da resposta da estudante.
} 
VIII Congresso Brasileiro de Informática na Educação (CBIE 2019)

Anais do XXV Workshop de Informática na Escola (WIE 2019)

\section{Conclusão}

Este artigo abordou a aplicação de uma proposta de ensino de lógica de programação, voltada para o público feminino, na busca de fomentar e aumentar o número de meninas nas ciências, em especial na computação. A experiência buscou, não somente, despertar, motivar e ampliar o interesse das meninas para a áreas onde são minorias, mas também apresentar informações úteis para a vida, mesmo para as meninas que não querem seguir esse caminho.

Como resultado, viu-se que para as meninas que permaneceram, o aprendizado foi uma abertura de portas, possibilitando a ver outra área de estudo, que possa ser uma opção para o futuro. Para novos trabalhos, pode ser verificado se a aprendizagem exclusiva para as meninas, realizado nesse primeiro momento pode aumentar o nível de confiança e motivação nelas, comparando a aplicação da mesma proposta com uma oficina não-exclusiva. Estudos dos pontos motivacionais para o ensino de computação voltado às meninas, mapeamento da participação da meninas na área da ciência da computação, entre outros.

\section{Referências}

Barbosa, G. et al. (2018). Play(code): Uma proposta para estimular o aprendizado de Lógica de Programação. In: Anais do XXIX Simpósio Brasileiro de Informática na Educação (SBIE 2018).

Mattos, F.; Ferreira, V.; Anacleto, J. (2016). O Ensino de Programação com Scratch e seu Impacto na Opção Profissional para Meninas. Anais do Xxvii Simpósio Brasileiro de Informática na Educação (SBIE 2016), [s.1.], p.300-309, 7 nov. 2016. Sociedade Brasileira de Computação - SBC.

Oliveira L.C.; Ribeiro, G. G.; Machado, A. F. V. (2015).Introdução à Lógica de Programação Utilizando Robôs Educacionais para Crianças do Ensino Básico. In: SBC - Proceedings of SBGames 2015, Culture Track - Short Papers, ISSN: 2179-2259.

Silva, L.S.; Cavalcanti, E. R. (2018). Avaliação Experimental do Robomind no Ensino de Programação com Estudantes do Curso Técnico em Informática Integrado ao Ensino Médio. In: Anais do XXIX Simpósio Brasileiro de Informática na Educação (SBIE 2018).

Souza, D.M.; Batista, M. H. da S. e Barbosa, E. F. (2016) "Problemas e Dificuldades no ensino e na Aprendizagem de Programação: Um mapeamento sistemático". Revista Brasileira de Informática na Educação, v. 24, n. 1, p. 39-52.

Simon, B.; Hanks, B.; McCauley, R.; Morrison, B.; Murphy, L. e Zander, C. (2009) "Forme, programming is ...". In Proceedings of the fifth international workshop on Computing education research workshop (ICER'09) (Berkeley, CA, USA, August 10-11, 2009). 2009.

Wazlawick, R. S. (2016). História da Computação. 1. ed. Rio de Janeiro: Elsevier, 2016. $584 \mathrm{p}$. 